\title{
Using the Response to Intervention (RtI) Service Delivery Model in Middle and High Schools
}

\author{
Pam Epler \\ Murray State University, USA
}

\begin{abstract}
This case study researched how the Response to Intervention (RtI) service delivery model is used within the secondary educational environment. Areas researched included the type of professional development used to introduce and sustain RtI, the amount of administrative support, the use of universal screenings, the type of data collected, and the instructional strategies used at each tier. Three teachers and one school counselor were interviewed using open-ended questions, classroom observations were conducted, and state and student report cards were evaluated for this study. The findings concluded that RtI was successful; however, each school had to look at its resources and devise a plan that best fit the school. This research implies that more studies need to be done on this topic to determine whether RtI can make a difference in secondary schools.
\end{abstract}

\section{Introduction}

Response to Intervention (RtI) has been in existence for only a short period, yet it has had a powerful impact on the academic achievement of students across the United States [1-5]. The National Center on Response to Intervention defined Response to Intervention as a delivery service model that integrates assessment and intervention within a multi-level prevention system to maximize student achievement. With Response to Intervention, schools identify students at risk for poor learning outcomes, monitor student progress, provide evidence-based interventions and adjust the intensity and nature of those interventions depending on a student's responsiveness, and identify students with learning disabilities or other disabilities [6].

According to Cummings et al. [7], RtI has reduced the number of special education referrals and has increased student achievement through the use of research-based instructional strategies. Students have also been able to receive additional academic assistance with their peers while in the regular education classroom environment. In addition, Woodruff [8] and Hosp [9] stated that disproportionally, the number of students that are over represented in special education, such as students living below the poverty line or students whose first language is not English, has been reduced through the implementation of RtI. Using this service delivery model, teachers can identify any learning difficulties and make necessary modifications to the curricula while the student is in the regular classroom.

\section{Background of the study}

According to Duffy [10], since the 1970s, the method for identifying students for special education services has traditionally been the discrepancy model. This model identifies the inconsistency between a student's IQ and his or her academic abilities as diagnosed by a battery of assessments. The weakness of this method is that the student has to fail or fall behind his or her peers significantly before being recommended for special educational testing. In some cases, students have fallen several years behind their peers, which have caused not only academic difficulties but behavioral problems as well. According to Martin [11] and Wedl [12], as a result of this challenge, researchers attempted to devise a method that would eliminate the discrepancy model and have students obtain academic assistance at a much quicker pace. Hence, the RtI model [13] was developed. This service delivery model allows students to receive academic support at a much earlier stage in their academic careers. Although RtI has been available for school districts to use for more than 30 years under such names as the Teacher Assistance Team Model, PreReferral Intervention Model, Mainstream Assistance Team Model, School-Based Consultation Team Model, and Problem-Solving Model [1], it was not until the reauthorization of the federally legislated Individuals with Disabilities Education Act (IDEA) in 2004 that school districts acknowledged this model as an alternative method to identify students with learning disabilities. 


\section{Challenges to RtI}

Duffy [10] suggested a number of challenges that the RtI model reveals in the secondary educational environment. First, locating age-appropriate universal screening and progress-monitoring tools can be a difficult task, as most stop at the eighthgrade reading level. At the elementary level, the most common screening method for reading difficulty is the Dynamic Indicator of Basic Early Literacy Skills (DIBELS). This tool is administered individually to students in Grades K-6. Unfortunately, at the secondary level, there is no such diagnostic tool readily available and, hence, the screening and progress monitoring becomes a challenge. Second, in high schools, students are required to take a variety of classes, which can present a challenge when trying to find ageappropriate interventions to work in more than one academic content area. Students at the secondary education level are reading for content mastery and comprehension. Thus, finding interventions that are not only age appropriate but also developmentally suitable can be a challenge.

Third, implementation of the RtI model can cause difficulties with such things as the overall program structure, how students move through the process, the sequence of activities within tiers, timelines, the balance between flexibility and consistency of cut scores for tiers [10]. It also has been suggested that because some middle and high schools draw from culturally diverse populations, it is important to take these differences into consideration when establishing an RtI model so that disproportionality does not occur [10].

Fourth, placing the RtI service delivery model into a secondary educational environment will cause the traditional teaching role of the regular and special education teacher to change. Special and regular education teachers will need to be trained to work collaboratively in a co-teaching classroom where both are treated as equal partners. Regular education teachers will need to expand their repertoire of intervention strategies to encompass all students. Some teachers may find this change overwhelming because their secondary education instruction did not prepare them for this level of instruction, whereas others will accept it, knowing that student achievement is the ultimate goal [10].

Fifth, in order to make gains toward academic achievement, secondary teachers must use researchbased instruction strategies in all content areas to ensure the most effective teaching methods are being implemented. Without this type of aforementioned instruction, students will not make any progress toward achieving their academic goals [10]. Sixth, most middle and high schools have established time in the teachers' schedules to meet weekly with their particular content area department. However, with the RtI model, it is essential that teachers not only follow through with the aforementioned but that they also collaborate with other content area departments as well. They must additionally have time to meet with the RtI team to discuss student progress [10].

Seventh, consistent and relevant professional development on the RtI model is essential to the program's success, and the professional development should include such things as an introduction to RtI, assessment methods and interpretation, effective teaching strategies, and best practices for monitoring progress and using that data to inform instructional interventions [10]. Finally, most middle and high schools have limited parental involvement. However, in order for the RtI model to be effective, schools at the secondary level must reach out and elicit more parental participation in all aspects of the RtI service delivery model so that students can reach their academic potential [10].

Clearly, the RtI service delivery model faces challenges when implemented in secondary schools. All the aforementioned challenges will have to be overcome if RtI is to be successfully used in the middle and high school learning environments.

\section{RtI Models}

RtI is a multi-tiered model (see Figure 1) used to improve academic achievement obstacles in a school environment [14]. The National Center on Response to Intervention [15] stated that RtI is a multi-tiered model of service delivery in which instruction is differentiated to meet learner needs at various levels. Several specific factors or dimensions help distinguish among interventions at the various tier levels. In general, a higher degree of specificity and intensity is associated with a higher tier of intervention. The RtI service delivery model can and is also being used at the secondary education level to assist in identifying students who are at risk of academic failure and who need more intensive instructional interventions [14].

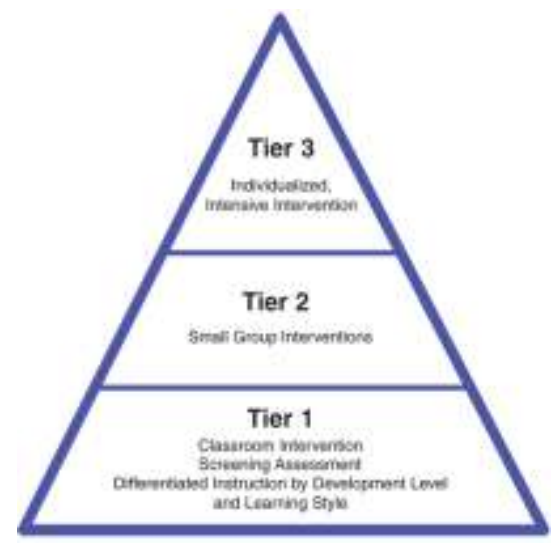

Figure 1. Rtl model [16] 
Throughout the literature, there are several different RtI models [3, 7, 10, 14, 17, 18]. There is a five-tiered model, a four-tiered model, and the one that most school districts use, the three-tiered model. All of these prototypes are shaped like a triangle, with the least restrictive components at the bottom and the more restrictive components at the top (see Figure 1). In each model, the student is assessed and the data from this evaluation are used to make informed decisions about the types of interventions the student requires and what will best fit the student's particular needs. Glover and DiPerna [19] stressed that regardless of the model type the school district is using, reporting accurate data and collecting evidence from each academic area is of utmost importance in order to determine whether or not the student is responding adequately to the intervention. Teachers and schools also must have an arsenal of research-based instructional strategies ready to assist with a variety of learning styles for this at-risk population, despite the RtI model chosen. Regardless of the model, students pass through each tier or level at their own rate. After numerous educational strategies have been tried and data collected, and it is determined that adequate academic progress is not being made, the student is moved to the next tier, which involves more intense interventions. When the student arrives at the top level, he or she is evaluated for special educational services [11].

\section{Tiers}

The components of the three-tiered RtI model start with interventions made within the general educational classroom and progress through various detailed tiers prior to the student being recommended for special education services. Each tier has its own unique parts, and the student must achieve academic success to avoid having to move to the next, more intense tier. A description of each tier follows.

\subsection{Tier I}

There are several components that define Tier I of the three-tiered RtI model. According to BrownChidsey [3], Tier I must include the following:

Universal instruction and an assessment are given to all students who are in the general education curriculum. Schools need to ensure that this instruction and assessment are research-based and effective in helping students gain academic proficiency. Success at Tier One is defined as the student demonstrating at least the levels of knowledge and skill expected for his age and grade. (p. 41)
Canter et al. [4] also argued that a student entering Tier I must have classroom instructional strategies that are research-based and follow a standards-based curriculum. On this level, the teacher and school district must engage in some kind of universal assessments, curriculum-based measurements, or informal evaluations to identify students who are academically behind their peers. Once this has been determined, the school, through collaboration with special and regular education teachers, must determine which supportive instructional strategies will be used within the classroom environment.

Fuchs and Deschler [18] revealed that no instructional program or curriculum has been validated for use with all children and suggested that since educational strategies are not one-size-fits-all, schools using the RtI model must design a vetting process to determine which instructional strategies are successful with their students and which are not. They also maintained that although between 2 to $6 \%$ of students do not respond to scientifically valid instruction, many students benefit from Tier 1 instruction.

Johnson and Smith [20] posited that differentiated instruction should be used within Tier I and maintained that it is imperative for schools to develop a method of data collection that is teacher friendly so that information can be easily gathered and analyzed, as data from the curriculum-based assessments need to be collected from all academic content areas.

\subsection{Tier II}

If a student has not been academically successful at Tier I, he or she moves to Tier II, and instructional strategies become much more intensive. Learning is conducted in a small group environment. Canter et al. [4] revealed that the criteria for the Tier II level includes (a) a small group environment, (b) monitoring of the student's progress after each intervention, (c) instructional modification and assessment for those students who did not adequately respond to Tier 1 strategies, and (d) specific interventions that are created and implemented as needed.

In Tier I, the instructional strategies or interventions are more generalized and can benefit anyone in the general educational curriculum. However, in Tier II, interventions are targeted to a specific academic skill and are provided for approximately eight to 12 weeks [14]. Like Tier I, the data collected and analyzed in Tier II are essential after each intervention to evaluate its effectiveness.

According to Brown-Chidsey [3], in Tier II, students are monitored after each intervention to determine academic accomplishments. If academic 
progress is made, the student is slowly weaned off his or her support system until he or she can go back into the regular education classroom environment. If after a designated period the student has not made adequate progress, the school or teacher selects another intervention strategy related to Tier II and the process is repeated. If after several attempts of adjusting Tier II modifications the student is still not making adequate progress, referral is made to Tier III. Evaluation for special education services will then begin.

Fuchs and Deschler [18] stressed the importance of student responsiveness under Tier II. They suggested different assessments, such as the Woodcock-Johnson Reading Mastery, Key Math, or DIBELS, to evaluate a student's academic abilities. The Woodcock-Johnson Reading and the Key Math tests can be used at any grade level for assessment, collection, and analysis of student achievement data. The DIBELS is limited to elementary and middle school levels.

\subsection{Tier III}

Once students have progressed through Tier II and have shown no signs of improvement or academic success, the next step in the RtI model is Tier III. Here, students may be evaluated for special education services, but this is not necessarily the norm. During Tier III, instructional strategies and interventions become individualized, are more intensive, and continue for a longer period of time. Data collected from Tiers I and II become vital in the determination of whether or not special education evaluation should proceed or whether the student needs more in-depth instructional assistance.

\section{Components of Successful RtI Models}

In order to have an effective RtI model, several researchers [4, 5, 7] suggested that the following elements must be in place. First, the school administration must support the concept of RtI without trepidation and must advocate for the implementation of scientific and research-based instruction. Second, an established universal screening agenda and recurrent progress monitoring must be in place. Next, teachers and administrators must be trained to collaboratively problem solve via the collection, implementation, and monitoring of the data through the use of curriculum-based measurement assessments that will determine if adequate progress is being made. Finally, there must be continuous professional development to ensure that all instructional staff and administrators are maintaining a level of integrity so that the data collected are validated and the student's progress is recorded efficiently and is easily accessible to all stakeholders. A plan should also be developed to evaluate the RtI model for effectiveness.

Bergstrom [2] concurred that professional development is an essential component of a successful RtI service delivery model. According to Bergstrom, in order for training to be advantageous, the following five components must be in place ( $\mathrm{p}$. 26):

1. Highly qualified trainers must be available to ensure that teachers receive the preparation necessary for a successful RtI model. Trainers must also be accessible to follow up after the initial training session to answer any questions or concerns teachers may have.

2. "Commitments and active involvement of school administrators" are required. All stakeholders, especially the school leaders, must be actively engaged in and committed to the RtI service delivery model if it is going to be successful and improve student achievement.

3. The realization that "effective leadership teams play a major role in successful implementation" must exist. Collaboration is an essential component of the RtI service delivery model and must occur if it is to be successful. Teachers and administrators have to be given time, at least weekly, to meet and discuss challenges that may arise within the RtI process.

4. "The quality data management systems to facilitate data-based decision-making" must be utilized. Teachers must be educated about utilizing data to not only improve classroom instructional strategies, but also analyze and interpret the information to determine whether the student needs additional services to increase academic outcome.

5. "Strategic team planning time and networking opportunities across sites" must be valued. In school districts where the RtI service delivery model is used throughout every building, it is vital for teachers to collaborate with other schools to discuss strategies and interventions that were successful as well as approaches that did not work as well at their school.

In addition, Canter et al. [4] stated that not only is it critical to have school administration and teaching staff support for the success of the RtI model, but it is vital to include parental support as well. Parents should be included in all aspects of the RtI model, from the initial onset of the program through the assessment process, as collaboration between home and school is essential to the success of any assessment or intervention. Furthermore, administrators need to know their respective state's laws concerning the No Child Left Behind (NCLB) legislation for qualifying students for special education services, and administrators and staff should implement one tier per year and coordinate their efforts with all grade levels for consistency. Finally, the authors suggested that the RtI model be 
integrated into the existing middle or high school schedule because "block scheduling can provide an effective framework for modified instruction and scheduled study halls can be used for skill labs and dropout prevention programs" (p. 15).

The Center for Comprehensive School Reform and Improvement [21] also compiled a list of components that must be in place if a secondary school wants to have a successful RtI service delivery model. These include:

1. All instruction included in the RtI service delivery model must be scientifically based and must increase with intensity as the tiers progress.

2. Students' academic abilities must be evaluated on a regular basis to determine success or failure.

3. Interventions at each tier must be monitored through the use of data. If necessary, adjustments must be made to accommodate a student's needs.

4. Fidelity must be implemented and maintained throughout the entire RtI service delivery model process.

Furthermore, Reutebauch [22] suggested 10 guidelines for a successful RtI service delivery model at the secondary education level (pp. 1-2):

1. "Implement research validated instructional supports to ensure that all students are receiving high-quality practices". By using research-based instructional strategies, the teacher can be assured that these practices have been used and evaluated by researchers and hence have a basis for validity.

2. "Begin prevention and intervention early for the biggest gains". One of the reasons for eliminating the discrepancy model as the sole method for identification of special educational services is so that students do not have to wait for a lengthy period prior to receiving assistance. Identifying academic difficulties early is an advantage of RtI.

3. "Offer multiple levels of intervention". At each tier, instruction should intensify and be aligned to student needs. By setting goals for each student and monitoring the data on a continuous basis, students will not be at one tier for any length of time. Instead, the tiers are fluid, which allows students to move according to their needs. Also, as instruction at each tier intensifies, the number of students serviced decreases, giving students more individualized instruction.

4. "Adopt an individual problem-solving model or standardized intervention protocol to provide struggling students with early, effective instruction and to present a valid means of assessing their learning needs". Both protocols are used in the secondary educational environment to assess whether or not a student needs additional services. The problem-solving approach involves a team of educators determining the individual interventions for the student as opposed to the standard protocol, which follows a research-based standard intervention for the student.

5. "Use fidelity checks to measure whether instruction is implemented as intended and with consistency". Regular evaluation of both the instructional strategies and assessments of the student must be completed to ensure the success or failure of the intervention. Without fidelity, or using the instructional strategy or research-based intervention as it is intended to be used, the process becomes invalid.

6. "Identify students at risk for academic problems, monitor their responsiveness to classroom instruction, conduct frequent assessments to monitor progress or lack thereof of students receiving interventions beyond Tier, and use the results to adjust instructional practices accordingly". Students need to be assessed numerous times throughout the school year to determine eligibility for the RtI service delivery model program. This assessment should be both formal and informal via researchbased assessments and informal teacher-made assessments. Once students have been identified, frequent assessments are necessary to determine whether each student needs to remain at the same tier, move to a lower tier, or receive more intensive interventions.

7. "Differentiate instruction on the basis of data from ongoing assessments, incorporate a variety of grouping formats, and determine eligibility for special educational and related services through a comprehensive evaluation that is determined by a multidisciplinary team". Once data have been established via formal and informal assessments, teachers need to analyze the data and adjust their instructional strategies accordingly. This procedure needs to be a collaborative effort conducted on all tier levels. The use of groups will vary depending on the tier, with more individualized teaching occurring as the instruction becomes more intensified.

8. "Attend professional development to gain the necessary tools to provide high-quality instruction and to enhance implementation of scientifically based practices. Be open to follow-up support and ongoing professional development to increase teacher effectiveness. Receive consistent support for sustainability, whether through on-site coaching or mentoring, and develop an understanding of RtI and student achievement". Professional development is a continuous requirement if the RtI service delivery model is to be successful at the secondary education level. This support must not only occur at the start of the RtI model process but must be maintained and ongoing so that teachers can continuously improve upon their research-based instructional strategies. Like all professional development, teachers need to have constant support, not only about the RtI service 
delivery model but also within the academic content area.

9. "Set short-term goals for struggling students to help document, track their progress, and adjust these goals based on student progress. Develop a school wide plan for entry and exit from the tiers". Guidelines must be established determining when a student moves into the next tier, is removed from support all together, or is considered for special education services.

10."Design RtI practices that are culturally responsive to the populations being served and involve parents and families in the RtI process". Parents are an integral part of the RtI service delivery model, as they can provide support at home for what is happening at school. The RtI model should relate to the cultural differences of each student as well.

\section{Student Achievement and RtI}

Scammacca et al. [23] reviewed the literature and identified studies in which the Response to Intervention service delivery model was implemented to improve reading difficulties of atrisk students in twelve elementary schools, Grades $\mathrm{K}-3$. The data collected from these studies indicated that the interventions were implemented by a teacher on either the Tier I or II level during the course of a school year. The interventions occurred daily, and the length of the session varied from 10 to 60 minutes. The tier level instruction occurred either in the classroom or in a small group setting. The results of these studies showed that the students scored significantly higher on the post-test than the pre-test in regards to their reading abilities.

Newman-Gonchar et al. [24] found similar results when reviewing literature about mathematics and the use of the Response to Intervention service delivery model with at-risk students in nine elementary schools, Grades K-5. The data collected from these studies also indicated that the interventions were implemented by a teacher on either the Tier I or II level during the course of a school year. The interventions occurred daily, and the length of the session varied from 10 to 40 minutes. The tier level instruction occurred either in the classroom or in a small group setting. The results of these studies showed that the students scored significantly higher on the post-test than the pre-test in regards to their mathematical abilities.

The aforementioned research indicates that the interventions used in Tier I and Tier II within the Response to Intervention service delivery model are improving students' academic abilities. Thus, the number of special education referrals or students moving on to Tier III have been reduced [23].

In addition, the Center for Comprehensive School Reform and Improvement [21] conducted studies on several high schools throughout the United States concerning the RtI service delivery model. The studies showed how secondary schools increased student achievement through the use of the RtI model. The first study was conducted in a high school in Colorado that was using the RtI model. Over a 7-year period, the graduation rate increased from $76 \%$ to $84 \%$, the dropout rate decreased from $10 \%$ to less than $1 \%$, the freshman failure rate was reduced from $40 \%$ to $17 \%$, and on the overall state report card, the school went from a rating of average to high for 3 years in a row. Another study, conducted in Chicago, involved middle school students. These students were struggling with the mathematics portion of the state-mandated assessment. The students were placed into a math resource room instead of taking an elective course of their choice and were given additional math services. These additional services were continued throughout the middle school years and on into high school for students who needed extra support. Results showed that the students' scores on the state-mandated mathematics assessment increased.

In addition, Rozalski [25] conducted a study at a high school in West Virginia where the RtI service delivery model was used to improve students' reading abilities in all academic areas. Thirty students were identified as having reading difficulties and were placed in a group according to their abilities. The students placed in Tier I were given grade-appropriate core instruction in the regular classroom environment. In Tier II, students continued to receive regular classroom instruction and were given additional instruction in a resource room. Finally, in Tier III, students received instruction in the regular educational classroom as well as increased daily direct reading instruction time. The results of the study demonstrated an improvement in the students' reading abilities at all three tier levels. At Tier I, the students' fluency rate increased from the 9.9 grade level to the 10.0 grade level, their word identification improved from the 9.0 grade level to the 9.4 grade level, and their comprehension level increased from the 8.6 grade level to the 8.7 grade level. In Tier II, greater increases in academic achievement were found. The students' fluency rate increased from the 6.8 grade level to the 7.2 grade level, their word identification improved from the 6.0 grade level to the 6.5 grade level, and their comprehension level increased from the 6.1 grade level to the 7.2 grade level. Finally, in Tier III, an even greater increase was noted. The fluency rate increased from the 4.7 grade level to the 6.6 grade level, word identification improved from the 3.8 grade level to the 5.9 grade level, and comprehension increased from the 3.5 grade level to the 5.4 grade level.

The aforementioned studies illustrate that the RtI service delivery model has been successful at the middle and high school educational levels and that 
participating students' academic abilities improved. However, this is a very small population sample and, as a consequence, RtI must be studied on a much larger scale.

\section{Descriptive data for the case study}

In this qualitative, collective case study, two secondary schools that were currently using the Response to Intervention service delivery model were compared. Both School 1 and School 2 scored excellent, the highest ranking, on their state report cards for the 2009-2010 academic school year. Further comparisons of the two schools for the 20092010 school year can be found in Table 1.

Table 1. Comparison of state report cards for School 1 and School 2.

\begin{tabular}{|c|c|c|}
\hline & School 1 & School 2 \\
\hline Student Scores on & & \\
\hline \multicolumn{3}{|l|}{ Reading Assessment } \\
\hline Accelerated & $52.3 \%$ & $61.1 \%$ \\
\hline Proficient & $35.6 \%$ & $31.4 \%$ \\
\hline Failed & $12.1 \%$ & $7.4 \%$ \\
\hline \multicolumn{3}{|l|}{ Student Demographics } \\
\hline Economically Disadvantaged & $11.6 \%$ & $16.9 \%$ \\
\hline Special Education & $11.9 \%$ & $11.2 \%$ \\
\hline Limited English Skills & -- & $1.9 \%$ \\
\hline Yearly Attendance Rate & $94.3 \%$ & $95.4 \%$ \\
\hline Yearly Graduation Rate & $95.2 \%$ & $95.6 \%$ \\
\hline \multicolumn{3}{|l|}{ Degrees of Teacher } \\
\hline Bachelor's Degrees & $100 \%$ & $100 \%$ \\
\hline Master's Degrees & $54.7 \%$ & $56.9 \%$ \\
\hline
\end{tabular}

School 1 started the RtI service delivery model during the 2009-2010 school year after a change in school superintendents. They took a year to introduce the model to the teaching staff and then fully embraced it during the 2010-2011 school year. At the time of this study, the building administrator was responsible for RtI, and it was used throughout the entire school, which encompassed 570 students in Grades 7-12.

School 2 started the Response to Intervention process in 2004 with an academic performance room (APR), considered Tier II. This was the only intervention strategy outside of the regular education classroom, Tier I. During the 2010-2011 school year, with the change of the school building administrator, Tier III and professional learning communities (PLCs) were added to their RtI model. At the time of this study, the building administrator was responsible for RtI, and it was used throughout the entire school, which encompassed 1,453 students in Grades 9-12.

Both schools followed a four-tier RtI model and had the regular education classroom as Tier I. In Tier
II at School 1, the regular education teacher worked with the school counselor to decide on additional instructional strategies that the regular education teacher could use, and the students attended a special reading class. At School 2, the students attended a special study hall, called APR, where several content area teachers were available to assist students who were failing classes. For Tier III, School 1 held a meeting that teachers, parents, school counselors, and other stakeholders who may have a vested interest in the student attended to determine if more data needed to be collected or if additional instructional strategies, like small group tutoring, needed to be tried prior to recommending the student for special educational services (Tier IV). At School 2 , students in Tier III attended a special reading class during their study hall time several times a week to receive specific instruction in reading and writing prior to being recommended for special educational services. Further comparisons of the two schools' RtI service delivery models can be found in Table 2.

Table 2. Comparison of School 1 and School 2 Response to Intervention models.

\begin{tabular}{|c|c|c|}
\hline & School 1 & School 2 \\
\hline Number of Tiers & 4 & 4 \\
\hline Diagnostic Practice & $\begin{array}{c}\text { OAA/OGT } \\
\text { Report Cards } \\
\text { Teacher Report }\end{array}$ & $\begin{array}{c}\text { OGT } \\
\text { Report Cards } \\
\text { Teacher Report }\end{array}$ \\
\hline $\begin{array}{l}\text { Data Collection } \\
\text { Method }\end{array}$ & $\begin{array}{c}\text { OAA/OGT } \\
\text { Report Cards } \\
\text { Teacher Report }\end{array}$ & $\begin{array}{c}\text { OGT } \\
\text { Report Cards } \\
\text { Teacher Report }\end{array}$ \\
\hline $\begin{array}{l}\text { Instructional } \\
\text { Strategies }\end{array}$ & $\begin{array}{l}\text { Small Groups } \\
\text { Tutoring } \\
\text { Extra Time }\end{array}$ & $\begin{array}{l}\text { Small Groups } \\
\text { Tutoring } \\
\text { Extra Time }\end{array}$ \\
\hline $\begin{array}{l}\text { Professional } \\
\text { Development }\end{array}$ & Monthly & $\begin{array}{c}\text { Twice in } 3 \\
\text { years }\end{array}$ \\
\hline $\begin{array}{l}\text { Administrative } \\
\text { Support }\end{array}$ & Yes/Sometimes & Yes \\
\hline
\end{tabular}

Upon data analysis of the two schools, three themes emerged. One was that despite the different instructional strategies, the RtI service delivery model can be implemented and utilized within a secondary educational environment. The second was that administrative support on the building level is essential to the success of the RtI service delivery model. Finally, the third emergent theme was that professional development, in the form of PLCs, is important to the RtI service delivery model.

\section{RtI effectiveness}

Report card grade documentation from the school years 2009-2010 and 2010-2011 were collected from 
both schools. In one school, parental permission had to be obtained prior to the researcher being granted permission to view student files and, as a result, five parents granted this permission. In the other school, permission was granted by the school's superintendent, and the researcher was given access to 15 student files.

Students' reading grades from both School 1 and School 2 for the second semester of the 2009-2010 marking period and reading grades from the first semester of the 2010-2011 were compared. The results of the data collected from School 1 are located in Table 3, and the results of the data collected from School 2 are located in Table 4.

According to the data illustrated in Table $\mathbf{3}$, School 1 students 1B through 4B, 6B through 12 B, and $15 \mathrm{~B}$ all showed improvement in their language arts grades, and $1 \mathrm{~B}, 5 \mathrm{~B}$, and $7 \mathrm{~B}$ through $14 \mathrm{~B}$ passed the state-required reading test based on the RtI service delivery model instructional strategies that the teachers employed. Students $2 \mathrm{~B}$ through $4 \mathrm{~B}, 6 \mathrm{~B}$, and $15 \mathrm{~B}$, showed improvement in their language arts grades but did not pass the state-required reading assessment. Student 13B's grades remained the same for both semesters, and student 14B's grades decreased. Failure to pass the state reading assessment, a decrease in grades, or a lack of academic improvement could be due to a variety of factors, such as poor test-taking skills, excessive absenteeism, not feeling well on the day of the test, fidelity, or lack of proper resources.

Table 3. 2009-2010 reading grades: School 1

\begin{tabular}{|c|c|c|c|c|c|c|}
\hline Student & Tier & Grade & Gender & $\begin{array}{c}2009- \\
2010 \\
\text { Reading } \\
\text { Grade }\end{array}$ & $\begin{array}{c}2009- \\
2011 \\
\text { Reading } \\
\text { Grade }\end{array}$ & $\begin{array}{c}\text { October } \\
2009 \\
\text { OAA } \\
\text { Reading } \\
\text { Score } \\
\end{array}$ \\
\hline 1B & I & 9 & $\mathrm{~F}$ & C- & C & $\operatorname{Pr}$ \\
\hline $2 B$ & II & 9 & M & $\mathrm{F}$ & B & $\mathrm{Ba}$ \\
\hline $3 B$ & II & 9 & M & F & F & $\mathrm{Ba}$ \\
\hline 4B & III & 9 & $\mathrm{~F}$ & $\mathrm{~F}$ & C & $\mathrm{Ba}$ \\
\hline $5 B$ & I & 9 & M & C & D & $\operatorname{Pr}$ \\
\hline $6 \mathrm{~B}$ & I & 9 & $\mathrm{~F}$ & B- & $\mathrm{B}+$ & $\mathrm{Ba}$ \\
\hline 7B & I & 9 & M & C & B & $\operatorname{Pr}$ \\
\hline $8 \mathrm{~B}$ & II & 9 & M & $\mathrm{C}+$ & B & $\operatorname{Pr}$ \\
\hline $9 \mathrm{~B}$ & II & 9 & M & C- & B & $\operatorname{Pr}$ \\
\hline $10 \mathrm{~B}$ & II & 9 & M & B & A & $\operatorname{Pr}$ \\
\hline 11B & III & 9 & M & D+ & B & $\operatorname{Pr}$ \\
\hline $12 \mathrm{~B}$ & I & 9 & M & C & $\mathrm{C}+$ & $\operatorname{Pr}$ \\
\hline 13B & I & 9 & M & A & A & Ac \\
\hline $14 \mathrm{~B}$ & I & 9 & M & A- & A- & $\operatorname{Pr}$ \\
\hline $15 \mathrm{~B}$ & II & 9 & M & C & C & $\mathrm{Ba}$ \\
\hline
\end{tabular}

As shown in Table 4, at School 2, students $1 \mathrm{~N}$ through $4 \mathrm{~N}$ showed improvement in their language arts grades and passed the state-required reading test based on the RtI service delivery model instructional strategies that teachers employed. Student $5 \mathrm{~N}$ showed improvement in the language arts grades but did not pass the state-required reading assessment and was required to retake the test. Again, failure to pass the state reading assessment, a decrease in grades, or a lack of academic improvement could be due to a variety of factors, such as poor test-taking skills, excessive absenteeism, not feeling well on the day of the test, fidelity, or lack of proper resources.

Table 4. 2009-2010 reading grades: School 2

\begin{tabular}{lcccccc}
\hline Student & Tier & Grade & Gender & $\begin{array}{c}2009- \\
2010 \\
\text { Reading } \\
\text { Grade }\end{array}$ & $\begin{array}{c}2009- \\
2011 \\
\text { Reading } \\
\text { Grade }\end{array}$ & $\begin{array}{c}\text { October } \\
2009 \\
\text { OAA } \\
\text { Reading } \\
\text { Score }\end{array}$ \\
\hline $1 \mathrm{~N}$ & I & 10 & F & D- & B & Pr \\
$2 N$ & I & 10 & F & A- & A & Ac \\
$3 N$ & III & 10 & F & D+ & B & Ad \\
$4 N$ & I & 10 & F & C & B & Ac \\
$5 N$ & III & 11 & M & F & C & Ba \\
\hline
\end{tabular}

Note. No parent whose student was involved in Tier II of the RtI service delivery model granted permission for the researcher to review his or her child's report card documentation. OAA is a required assessment for all eighth-grade students. There is no state-mandated testing for ninth grade. A score of Proficient or better is passing. Ac = Accelerated; Ad = Advanced; $\mathrm{Pr}=$ Proficient; $\mathrm{Ba}=$ Basic.

This qualitative, collective case study found that the Response to Intervention service delivery model differed between the two schools observed. Although each school had intervention strategies aligned to the various tiers, had building-level administrative support, both for the model and the teaching staff, and provided professional development, the methods these two schools used to accomplish RtI were quite different.

\section{Summary of the Study}

RtI is a service delivery model that helps in identifying students who need extra academic assistance. This qualitative, collective case study examined specifically how RtI was implemented at the secondary level in two northeastern Ohio schools. Both schools used a four-tiered model. At both schools, students who were struggling academically were given Tier I interventions, which were provided by the general classroom teacher. From the classroom observations and teacher interviews, intervention strategies including one-onone tutoring sessions, small group collaboration, chunking of materials, and exit passes to reinforce the concept taught in the classroom were noted at School 1. At School 2, Marzano et al.'s [6] instructional strategies, summarizing and note taking, asking questions and using advanced graphic organizers, assigning nightly homework, reinforcing student effort, and providing recognition to students were the interventions observed and discussed.

Within Tier II, the schools differed greatly. At School 1, Tier II interventions continued to be implemented by the classroom teacher. The difference between Tier I and Tier II was the type of intervention used. The type of intervention used for Tier II was discussed between the classroom teacher 
and the school's guidance counselor. School 2, on the other hand, provided students with a special study hall, or APR, in which academic content teachers were available to assist students in understanding a concept recently taught in the classroom or to help them with completing a neglected assignment. Students were assigned to APR if they had earned a D or F in a content area, such as math, English, science, or social studies, for the quarter grade marking period or had failed the state-mandated reading assessment. The students remained at this tier for the quarter grading period and could only be removed when their academic content area grade improved to a $\mathrm{C}$ or better or when they passed the state reading test.

Tier III also differed greatly between the schools. At School 1, students received Tier III interventions through small group meetings, one-on-one tutoring sessions, or credit recovery programs. At School 2, students were taken from their APR several times weekly and given additional reading assistance by a state-certified reading teacher. Students remained at this tier until they passed the state-mandated reading test.

If a student had completed the three tiers but had not demonstrated academic success, the student was evaluated for Tier IV, which, at both schools, was a special education service. The process of moving from Tier I to Tier IV took approximately 1 year to complete, and teachers were trained on how to collect the necessary data to support special education placement.

At both schools, professional development about RtI was conducted, although more intently at School 1 than at School 2. In addition, three out of the four teachers interviewed felt that the school administrator supported them and the RtI process, while one teacher felt that the school administrator, although supportive, needed to learn more about the RtI service delivery model.

\section{Implications of the Study}

It is hoped that as a result of this research, more studies on middle and high schools that are actually using RtI will emerge. One-size-fits-all is not what the RtI service delivery model is all about; instead, it involves devising a plan that best fits the school. By conducting more studies, similarities and differences will start to emerge, which will allow schools to start thinking about the RtI service delivery model and decide what works best for them. For the second and third tiers, schools need to be creative when deciding how to provide services for the students, and if there are studies that have looked at a variety of secondary models, it will be easier to put things into place as opposed to reinventing the wheel.

This research implies that the RtI service delivery model can be used within the secondary educational learning environment but that each school is going to have to look at its resources and figure out what services it can provide at each level. Some schools may be able to provide a reading specialist, whereas other schools may have to depend on tutors to provide help. Some schools may opt to have only three tiers, as opposed to the four researched here, due to budget constraints.

For the two schools researched, the RtI service delivery model was successful, but more studies need to be conducted about the Response to Intervention service delivery model to determine whether this model is one that can help promote student success at the secondary educational level.

\section{References}

[1] All Kinds of Minds. (2008). 'IDEA: Response to Intervention and Schools Attuned', Policy Brief 1(1); http://www.allkindsofminds.org/library/reach-morelearners/policybrief-idea-rti-sa.pdf (6 May 2010).

[2] Bergstrom, M. K. (2008) 'Professional Development in Response to Intervention: Implementation of a Model in a Rural Region', Rural Special Education Quarterly 27(4), pp. 27-36.

[3] Brown-Chidsey, R. (2007) 'No More "Waiting to Fail”, Educational Leadership 65(2), pp. 40-46.

[4] Canter, A., Klotz, M. B. and Cowan, K. (2008) 'Response to Intervention: The Future for Secondary Schools', Principal Leadership 8(6), pp. 12-15.

[5] Coulter, W. A. (n.d) 'Making Sense of Response to Intervention: Critical Tools for a Critical Time'; http://nasdse.org (6 May 2010).

[6] Marzano, R., Pickering, D.J. and Pollack, J.E. (2001) Classroom Instruction That Works, ASCD, Alexandria, VA.

[7] Cummings, K., Atkins, T., Allison, R. and Cole, C. (2008) 'Response to Intervention: Investigating the New Role of Special Educators', Teaching Exceptional Children 40(4), pp. 24-31.

[8] Woodruff, D. (2011) 'Why is RtI an Important Strategy for Addressing Disproportionality?'; http://www .rti4success.org (2 January 2012).

[9] Hosp, J. (2010) 'Does RtI Have the Potential to Reduce Disproportionality in Special Education?'; http://www.rti4success.org (3 February 2011).

[10] Duffy, H. (2007) 'Meeting the Needs of Significantly Struggling Learners in High School: A Look at Approaches to Tiered Interventions'; http://www.air.org /highschool (14 April 2009).

[11] Martin, J. (2007) 'Implementing Response to Intervention at the High School Level: Every Student, 
Every Day!'; http://www.nwrel.org/nwrcc/rti-webinar /materials/rti-dhs.pdf (15 October 2009).

[12] Wedl, R. J. (2005) 'Response to Intervention: An Alternative to Traditional Eligibility Criteria for Student with Disabilities', Education Evolving, pp. 1-22; http://www.educationevolving.org (3 February 2010).

[13] Elliot, J. (2008) 'Response to Intervention: What \& Why?' School Administrator 65(8), pp. 10-17.

[14] Grimes, J. and Kurns, S. (2003) 'A Multiple Tiered Model to Ensure Every Child Learns', Paper presented at the National Research Center on Learning Disabilities Responsiveness-to-Intervention Symposium, Kansas City, MO.

[15] National Center on Response to Intervention (2010) 'Essential Components of RtI: A Closer Look at Response to Intervention'; http://www.rti4success.org (12 April 2011).

[16] Moving with Math (2010) 'Response to Intervention: Assessment'; http://www.movingwithmath.com/learningsystem/response-to-intervention (12 April 2011).

[17] Barton, R. and Stepanek, J. (2009) 'Three Tiers to Success', Principal Leadership 9(8), pp. 16-21.

[18] Fuchs, D. and Deschler, D. D. (2007) 'What We Need to Know About Responsiveness to Intervention (and Shouldn't Be Afraid to Ask)', Learning Disabilities Research \& Practice 22(2), pp. 129-136.

[19] Glover, T. A. and DiPerna, J. C. (2007) 'Service Delivery for Response to Intervention: Core Components and Directions for Future Research', School Psychology Review 36(4), pp. 526-540.

[20] Johnson, E. S. and Smith, L. (2008) 'Implementation of Response to Intervention at Middle School: Challenges and Potential Benefits', Teaching Exceptional Children 40(3), pp. 46-52.

[21] The Center for Comprehensive School Reform and Improvement (2008) 'Response to Intervention: Possibilities for Service Delivery at the Secondary School Level'; http://www.centerforcsri.org (3 February 2010).

[22] Reutebauch, C. K. (2008) 'Succeed with a Responseto-Intervention Model', Intervention in School and Clinic 44(2), pp. 126-129.

[23] Scammacca, N., Vaughn, S., Roberts, G., Wanzek, J. and Torgesen, J. K. (2007) Extensive Reading Interventions in Grades K-3: From Research to Practice, RMC Research Corporation, Center for Instruction, Portsmouth, NH.

[24] Newman-Gonchar, R., Clarke, B. and Gersten, R. (2009) A Summary of Nine Key Studies: Multi-tiered Interventions and Response to Intervention for Students Struggling in Mathematics, RMC Research Corporation, Center for Instruction, Portsmouth, NH.
[25] Rozalski, M. E. (2009) 'Response to Intervention: A Rural High School's Attempt to Improve Reading Achievement'; http://www.cec.sped.org (15 October 2009).

[26] Ohio Department of Education (2010) 'Ohio Department of Education 2009-2010 State Report Card'; http://www.ode.state.oh.us (15 January 2011). 